\title{
Cholangioscopy findings in IgG4-related sclerosing cholangitis
}
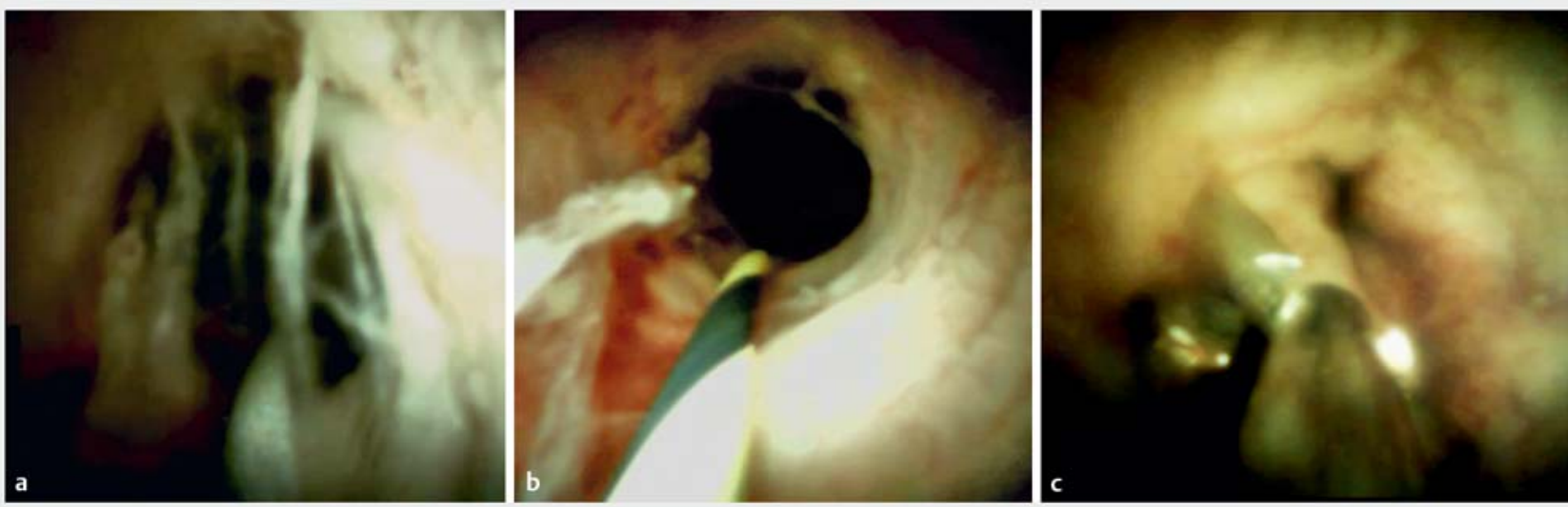

- Fig. 1 Endoscopic views showing: a loss of vascular markings due to engorgement of the mucosa; $\mathbf{b}$ edema and friability on contact; c a through-the-scope forceps biopsy being taken.

We present three cases of IgG4-related sclerosing cholangitis in association with autoimmune pancreatitis. The patients were all men and were aged 69, 71, and 75; their clinical presentations were with obstructive jaundice and considerable weight loss.

Computed tomography (CT) scans showed pancreatic head masses in all three patients, mimicking pancreatic malignancy. Magnetic resonance imaging (MRI) scans showed the biliary trees contained multiple areas of common bile duct stenosis and diffuse parietal thickening of the common bile duct wall. Two of the patients also had intrahepatic biliary involvement. Endoscopic ultrasound scans were performed with needle biopsies taken, the results of which were negative for malignancy but also negative for IgG4. Plasma levels of IgG4 were elevated in all of the patients (five times above the upper limit). Oral corticosteroids were initiated.

After 3 weeks of treatment, the clinical status of the patients markedly improved but the cholestasis persisted. New imaging studies were performed, which showed that the pancreatic head mass had almost disappeared in all three pa-

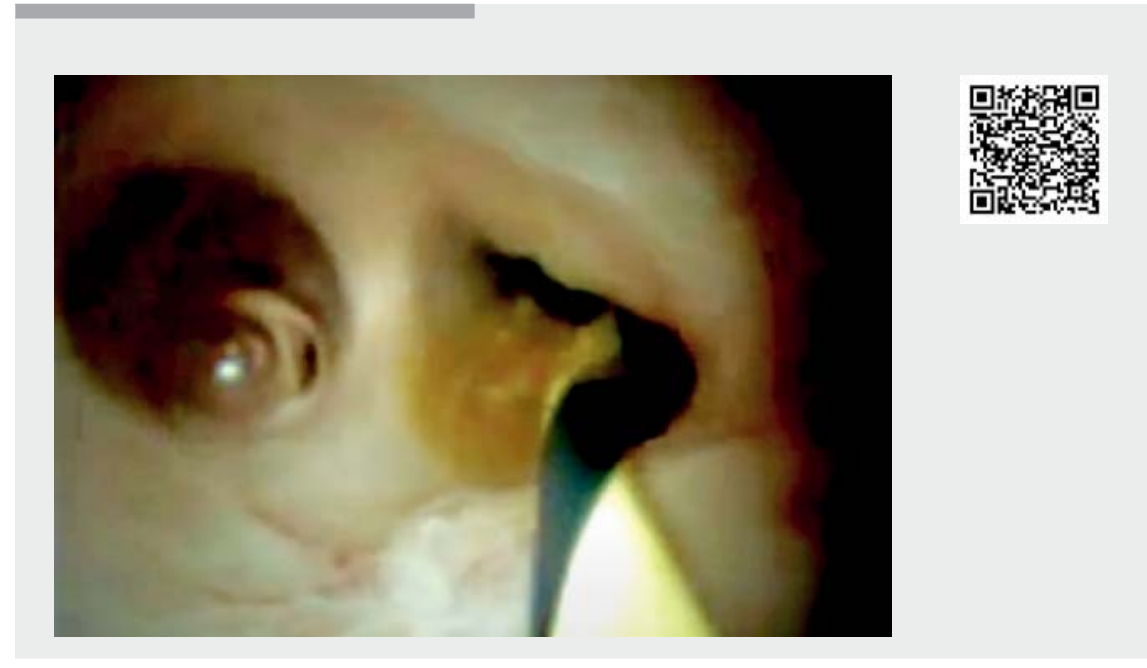

$\checkmark$ Video 1 Endoscopic findings in three patients with IgG4-related sclerosing cholangitis.

tients, but the biliary tract compromise was still present. We decided to perform peroral cholangioscopy, which showed diffuse involvement of the biliary tree with patchy areas of erythema and mucosal friability ( Fig.1; \ Video 1). Biopsies were again negative for malignancy and for IgG4. After 6 weeks of corticosteroids, the patients no longer had evidence of cholestasis and the new MRI scans showed improvement of the biliary tree stenoses, along with disappearance of the pancreatic head masses.

IgG4-related sclerosing cholangitis is frequently associated with autoimmune pancreatitis and is currently recognized as a biliary manifestation of IgG4 systemic disease [1]. The differential diagnosis from primary sclerosing cholangitis and cholangiocarcinoma is sometimes diffi- 
cult [2]. Peroral cholangioscopy has numerous applications in the diagnosis and treatment of various biliary disorders and can be a helpful diagnostic method to rule out malignancy in patients with IgG4-related sclerosing cholangitis [3].

Endoscopy_UCTN_Code_TTT_1AR_2AK

\section{Competing interests}

The authors declare that they have no conflict of interest.

The authors

Augusto Villaverde, Fernando Ignacio

Giménez, Dante Manazzoni, Juan E. Pizzala, Victor H. Abecia, Manuel Alejandro Mahler, Mariano M. Marcolongo

Gastroenterology Department, Hospital Italiano de Buenos Aires, Buenos Aires, Argentina
Corresponding author

Fernando Ignacio Giménez, MD

Gastroenterology Department, Hospital Italiano de Buenos Aires, Perón 4190, Zip code: C1199ABB, Buenos Aires, Argentina fernando.gimenez@hospitalitaliano.org.ar

\section{References}

[1] Umehara H, Okazaki K, Masaki Y et al. Comprehensive diagnostic criteria for lgG4related disease (IgG4-RD). Mod Rheumatol 2012; 22: 21-30

[2] Sanahuja Martínez A, Pascual Moreno I, Peña Aldea A et al. Usefulness of digital cholangioscopy for IgG4-related cholangitis diagnosis and cholangiocarcinoma exclusion. Gastroenterol Hepatol 2019; 42: 625-627

[3] Itoi T, Kamisawa T, Yoshinori I et al. The role of peroral video cholangioscopy in patients with IgG4-related sclerosing cholangitis. J Gastroenterol 2013; 48: 504-514

\section{Bibliography}

Endoscopy 2021; 53: E289-E290

DOI 10.1055/a-1264-6736

ISSN 0013-726X

published online 8.10 .2020

(c) 2020. Thieme. All rights reserved.

Georg Thieme Verlag KG, Rüdigerstraße 14,

70469 Stuttgart, Germany

\section{ENDOSCOPY E-VIDEOS}

https://eref.thieme.de/e-videos

回回 Endoscopy E-Videos is a free

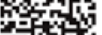
access online section, reporting on interesting cases and new techniques in gastroenterological endoscopy. All papers include a high quality video and all contributions are freely accessible online.

This section has its own submission website at

https://mc.manuscriptcentral.com/e-videos 